\title{
Formal Models of Scientific Inquiry in a Social Context: An Introduction
}

\author{
Dunja Šešelja $^{1} \cdot$ Christian Straßer $^{2} \cdot$ AnneMarie Borg $^{3}$
}

Published online: 9 April 2020

(c) Springer Nature B.V. 2020

\begin{abstract}
Formal models of scientific inquiry, aimed at capturing socio-epistemic aspects underlying the process of scientific research, have become an important method in formal social epistemology and philosophy of science. In this introduction to the special issue we provide a historical overview of the development of formal models of this kind and analyze their methodological contributions to discussions in philosophy of science. In particular, we show that their significance consists in different forms of 'methodological iteration' (Elliott 2012) whereby the models initiate new lines of inquiry, isolate and clarify problems with existing knowledge claims, and stimulate further research.
\end{abstract}

Throughout the last two decades philosophical discussions on scientific inquiry have increasingly utilized formal models. This has been especially fruitful for the investigation of social aspects of scientific inquiry, such as the division of cognitive labor, the epistemic effects of scientific interaction, the impact of biases on scientific research, etc. To this end a variety of formal models have been developed, from analytical ones to computer simulations in the form of agent-based models. One of the main advantages of formal approaches is that, in principle, they can help us to gain a precise understanding of the underlying issues and to form normative generalizations that are difficult to obtain in view of traditional methods (such as, for example, historical case studies). Nevertheless, models frequently come with a high degree of idealization and simplification, which may impede their reliability concerning actual scientific practice. This poses the question to which extent formal models can be used to provide an understanding of scientific inquiry, and to which extent they can be improved with respect to their relevance for science policy.

Dunja Šešelja

d.seselja@tue.nl

$\bowtie$ Christian Straßer

christian.strasser@rub.de

AnneMarie Borg

a.borg@uu.nl

1 Philosophy and Ethics Group, TU Eindhoven, Eindhoven, The Netherlands

2 Institute for Philosophy II, Ruhr University Bochum, Bochum, Germany

3 Department of Information and Computing Science, Utrecht University, Utrecht, The Netherlands 
In this introduction we provide a background to the topic of formal models of scientific inquiry (Sect. 1) and we analyze the role they play in the process of knowledge formation in philosophy of science (Sect. 2). Our focus here (as well as in this special issue) is on the models developed in the field of social epistemology of science, aiming to capture socio-epistemic dynamics of scientific inquiry. In Sect. 3 we give an overview of articles comprising this topical unit.

\section{The Development of Formal Models of Scientific Inquiry: Historical Background}

The philosophical study of scientific inquiry from a formal perspective gained a special interest with the introduction of economic approaches to social epistemology. The novelty of such approaches was that they introduced to social epistemology the mechanism of a 'generous invisible hand', according to which individuals interacting in a given community can bring about consequences that are beneficial for the goals of the community without necessarily aiming at those consequences (Mäki 2005, 213). For example, individuals driven by self-interest (such as fame) may under certain conditions bring about an adequate division of cognitive labor. Moreover, what is epistemically beneficial for an individual may differ from, or even conflict with what is epistemically beneficial for the given community.

While the tension between individual and group rationality had previously been discussed by Kuhn and others who advanced historicist theories of scientific rationality (Nickles 2017), formal methods inspired philosophers of science to get more precise insights into this tension. Early analytic models, such as those by Goldman and Shaked (1991) examining the relationship between the goal of one's professional success and the promotion of truth-acquisition, or Kitcher's model of the division of cognitive labor (Kitcher 1990; 1993), were followed by a number of related proposals (e.g. Bonilla 1999; Zamora Bonilla 2002; Strevens 2003). Soon, formal models of scientific inquiry employed computational techniques as well. While agent-based models (ABMs) of scientific inquiry had previously appeared in the field of sociology of science (e.g. Gilbert 1997; Edmonds 2008), they kicked off in social epistemology and philosophy of science with the pioneering works of Zollman (2007; 2010), Weisberg and Muldoon (2009), Grim (2009), Grim et al. (2013), Douven (2010) (building on the well-known Hegselmann and Krause's (2002) model), De Langhe (2014), among others. ${ }^{1}$

The development of formal models of science gave rise to the following two questions. First, which other problems concerning scientific inquiry can be fruitfully tackled by means of formal models? Second, how reliable are these models when it comes to normative conclusions about scientific inquiry? Can we take their findings as reliable information source for methodological, organizational or science-policy guidelines: for instance, can they inform us how to organize the reward structure of science, the organization of peer review, or the information flow among scientists?

More recently, discussions in the literature have been advancing along these two avenues. On the one hand, formal models have been suggested for the study of a range of

\footnotetext{
${ }^{1}$ For an overview of economic approaches to the modeling of scientific inquiry see Mäki (2005); for an overview of ABMs of science see Payette (2012); for an overview of models of the division of cognitive labor see Muldoon (2013).
} 
additional topics: from problems underlying the process of peer-review (Heesen 2018a), to the impact of biases on scientific inquiry (Holman and Bruner 2015; Weatherall et al. 2018), to belief polarization (O'Connor and Weatherall 2018; Bramson et al. 2017), to scientific collaboration (Boyer-Kassem and Imbert 2015; Boyer-Kassem et al. 2017), to argumentation strategies (Betz 2012; Borg et al. 2017; 2018), to epistemic stubbornness (Santana 2019) - to mention only some examples.

On the other hand, there has been a growing interest in studying the robustness and reliability of results obtained via previously proposed models, both analytic and agent-based ones (e.g. Muldoon and Weisberg 2011; Thoma 2015; Alexander et al. 2015; Pöyhönen 2017; Rosenstock et al. 2017; Frey and Šešelja 2018a; Borg et al. 2019). Moreover, a number of authors have emphasized the importance of relating the models with empirical data and providing empirical validation of the conclusions drawn from them (e.g. Martini and Pinto 2016; Harnagel 2018; Frey and Šešelja 2018b). The emergence of such methodological questions has been closely related to discussions on the methodology and epistemology of highly idealized models in social and natural sciences (e.g., Boero and Squazzoni 2005; Alexandrova 2008; Hindriks 2008; Arnold 2014; O’Sullivan et al. 2016, etc.).

In the next section we will take a closer look at some specific aspects of these two avenues that have been beneficial for the study of scientific inquiry.

\section{Methodological Contributions of Formal Models to the Study of Scientific Inquiry}

We have seen that formal models have become part of the toolbox of philosophical scholars, besides other methods such as historically informed ones. But how exactly do formal models contribute methodologically to the study of scientific inquiry? The notion of methodological iteration, introduced by Elliott (2012) can be clarifying in this context. As Elliott points out, the interplay of a plurality of methods can contribute to epistemic progress in a domain—what he calls with Chang (2004) epistemic iteration-by initiating new lines of inquiry, by isolating and clarifying problems with existing knowledge claims, and by stimulating further research on the given class of phenomena. ${ }^{2}$

We give some paradigmatic examples. First, formal models can be useful in generating new concepts and in the identification of relevant variables for a given phenomenon. An example is the concept of 'transient diversity' proposed by Zollman (2010). By means of an agent-based model of scientific inquiry Zollman discovered that if the agents diversify by researching different hypotheses for a significant time period, their success rate in converging on the right hypothesis increases, except the diversification rate is too high. 'Transient diversity' is a notion that marks the sweet spot. Several factors that influence this dynamics have been identified, such as the density of the information flow and the steadfastness of the agents in sticking to their inquiry despite counter-evidence.

Second, formal models can help isolate and identify problems with existing knowledge claims, localizing anomalies and sources of effects that are of interest. As a first example consider the problem of the self-correcting thesis of science, according to which scientific

\footnotetext{
${ }^{2}$ Elliot presents each of these functions as a type of interplay between methodological and epistemic iteration, where the former plays a role of initiating the latter, equipping it, and stimulating it. While Elliott's main focus are the natural sciences (his case study is in the field of nano-sciences), his analysis of methodological iteration can shed some light also on the role of formal models in our context.
} 
inquiry leads to closer and closer approximations of true theories. The validity of this thesis has traditionally been studied as a problem mainly concerning (statistical/inductive) inference. Romero (2016) tackles this problem from a social epistemological perspective and argues that realistic assumptions about social structures underlying scientific communities impose social 'constraints on scientists' work that make it impossible for them to correct their mistakes in the way that SCT [the self-correcting thesis] contends" (p. 56). In addition, Romero investigates implications of his study for the replicability crisis. Another example is the investigation of the replicability crisis in terms of a social choice model by Heesen (2018b). While the reward structure of science is usually discussed in a positive light as having a stimulating effect on scientific progress, Heesen's study highlights a problem that may come with it, namely scientific rewards as incentive to "rush into print" leading to a decrease in the quality of studies and therefore to reproducibility problems.

Finally, the mathematical analysis underlying formal models may assist in the identification of unexpected new problems and phenomena that require further investigation. For instance, formal models of the division of cognitive labor (such as the one by Kitcher 1990) highlighted the relevance of the reward structure of science and stimulated further investigation of this topic. Another example concerns discussions on peer disagreement. Formal models (e.g. by Douven 2010; De Langhe 2013) have stimulated the investigation of the epistemic norms proposed in the literature (such as the steadfast norm, according to which an agent should 'stick to her guns' in case she recognizes she is involved in a peer disagreement) in terms of their impact on the efficiency of scientific inquiry (for a recent discussion see Šešelja 2019).

In sum, we have followed roughly Elliott's distinction between the initiating role (e.g., by generating new regularities and concepts), the equipping role (e.g., by isolating and clarifying problems with existing knowledge claims), and the stimulating role (e.g., by assisting in the discovery of new problems) in which methodological iteration impacts the epistemic iteration. We have shown that formal models can contribute in each of these senses.

Nevertheless, it is important to notice that hypotheses generated by formal models, stemming from the frictionless space of mathematics, may in many cases profit from a back-and-forth with other methods such as those with an empirical and a historical emphasis. Unless we are merely interested in the abstract question 'how possibly a phenomenon may occur', that is, as soon as we are interested in the relevance of results obtained by means of formal models for their actual domain of application, we do well by turning to other methods as well.

This may, in a narrow sense, mean the usage of other formal models to study the (mathematical) robustness of results in order to check whether they are dependent on the specific idealizing assumptions of a given model (as it is done, for instance, in Borg et al. 2018; 2019). In a broader sense, by looking beyond the mathematical realm, we may turn to methods of empirical calibration (e.g. if we want to apply a model to a specific domain), or compare the behavior of real-life agents with the idealized agents from a model (e.g., Mohseni et al. 2019). Moreover, we may test hypotheses generated by models in view of historical studies (Frey and Šešelja 2018b), etc.

This type of cross-fertilization between formal and empirical methods is still scarce in the context of the study of scientific inquiry (probably due to the fact that formal methods are a recent development), but we expect to see more of it in the near future. 


\section{Overview of this Special Issue}

This special issue aims at contributing to the current literature on formal models of scientific inquiry by, on the one hand, introducing novel models (items 1-2 below), and by enriching the literature with methodological discussions on how such models should be developed, integrated and validated (items 3-5), on the other hand. The topical unit includes some of the papers presented at the conference Formal Models of Scientific Inquiry, held at Ruhr-University Bochum, July 18-19, 2017, as well as some additional contributions.

1. Cramer and Dauphin (2019) introduce a structured argumentation model, inspired by $\mathrm{ASPIC}^{+}$(Modgil and Prakken 2014), to study informal and semi-formal debates in formal sciences. An important novelty of the proposed framework with respect to ASPIC ${ }^{+}$ is that it incorporates explanations, following Šešelja and Straßer (2013). To show the usefulness of the model, the authors discuss debates around the Liar Paradox and the Axiom of Choice.

2. van Lee and Smets (2019) develop a logical model, based on Dynamic Epistemic Logic (Ditmarsch et al. 2007). The proposed Multi-agent Epistemic Observation Logic allows for the modeling of observation, interaction and belief revision in scientific communities. One of the advantages of this logical approach over Bayesian and simulation models is that it also allows for the modeling of higher-order reasoning, which plays an important role in scientific inquiry.

3. Perović and Sikimić (2019) discuss an integration between two types of assessments of scientific inquiry: the citation-based assessment, on the one hand, and inductive analysis, based on Formal Learning Theory, on the other hand. In order to show how this combination is beneficial for the understanding of scientific processes, the authors discuss two case studies: research in high energy physics and phylogenetic research.

4. Beni (2018) defends a probabilistic scientific realism with a pragmatic twist inspired by Feigl. For this he relies on insights from computational neuroscience, thereby addressing the relationship between scientific models and reality.

5. Finally, Thicke (2019) discusses the question how to evaluate formal models of science. To this end, he suggests that models should be assessed according to their predictive and representational accuracy, and that accordingly, most contemporary models of science fail to support normative claims.

Acknowledgements The research for this article and the preparation of the special issue was supported by a Sofja Kovalevskaja award of the Alexander von Humboldt Foundation, funded by the German Ministry for Education and Research, as well as by the Deutsche Forschungsgemeinschaft (DFG, German Research Foundation) - project number 426833574.

\section{References}

Alexander, J. M., Himmelreich, J., \& Thompson, C. (2015). Epistemic landscapes, optimal search, and the division of cognitive labor. Philosophy of Science, 82(3), 424-453.

Alexandrova, A. (2008). Making models count. Philosophy of Science, 75(3), 383-404.

Arnold, E. (2014). What's wrong with social simulations? The Monist, 97(3), 359-377. 
Beni, M. D. (2018). Reconstructing probabilistic realism: Re-enacting syntactical structures. Journal for General Philosophy of Science. https://doi.org/10.1007/s10838-018-9426-z.

Betz, G. (2012). Debate dynamics: How controversy improves our beliefs (Vol. 357). Berlin: Springer.

Boero, R., \& Squazzoni, F. (2005). Does empirical embeddedness matter? Methodological issues on agentbased models for analytical social science. Journal of Artificial Societies and Social Simulation, 8(4), 6.

Bonilla, J. P. Z. (1999). The elementary economics of scientific consensus. Theoria: An International Journal for Theory History and Foundations of Science, 36, 461-488.

Borg, A., Frey, D., Šešelja, D., \& Straßer, C. (2017). Examining network effects in an argumentative agent-based model of scientific inquiry (pp. 391-406). Berlin: Springer.

Borg, A., Frey, D., Šešelja, D., \& Straßer, C. (2018). Epistemic effects of scientific interaction: Approaching the question with an argumentative agent-based model. Historical Social Research, 43(1), 285-309.

Borg, A., Frey, D., Šešelja, D., \& Straßer, C. (2019). Theory-choice, transient diversity and the efficiency of scientific inquiry. European Journal for Philosophy of Science. https://doi.org/10.1007/ s13194-019-0249-5.

Boyer-Kassem, T., \& Imbert, C. (2015). Scientific collaboration: Do two heads need to be more than twice better than one? Philosophy of Science, 82(4), 667-688.

Boyer-Kassem, T., Mayo-Wilson, C., \& Weisberg, M. (2017). Scientific collaboration and collective knowledge: New essays. Oxford: Oxford University Press.

Bramson, A., Grim, P., Singer, D. J., Berger, W. J., Sack, G., Fisher, S., et al. (2017). Understanding polarization: Meanings, measures, and model evaluation. Philosophy of Science, 84(1), 115-159.

Chang, H. (2004). Inventing temperature: Measurement and scientific progress. Oxford: Oxford University Press.

Cramer, M., \& Dauphin, J. (2019). A structured argumentation framework for modeling debates in the formal sciences. Journal for General Philosophy of Science. https://doi.org/10.1007/s10838-01909443-z.

De Langhe, R. (2013). Peer disagreement under multiple epistemic systems. Synthese, 190, 2547-2556.

De Langhe, R. (2014). A unified model of the division of cognitive labor. Philosophy of Science, 81(3), $444-459$.

Ditmarsch, H. van, van der Hoek, W., \& Kooi, B. (2007). Dynamic epistemic logic. Berlin: Springer.

Douven, I. (2010). Simulating peer disagreements. Studies in History and Philosophy of Science Part A, $41(2), 148-157$.

Edmonds, B. (2008). Artificial science: A simulation to study the social processes of science. In B. Edmonds, K. G. Troitzsch, \& C. H. Iglesias (Eds.), Social simulation: Technologies, advances and new discoveries (pp. 61-67). Hershey, PA: IGI Global. https://doi.org/10.4018/978-1-59904-522-1.ch005.

Elliott, K. C. (2012). Epistemic and methodological iteration in scientific research. Studies in History and Philosophy of Science Part A, 43(2), 376-382.

Frey, D., \& Šešelja, D. (2018a). Robustness and idealization in agent-based models of scientific interaction. British Journal for the Philosophy of Science. https://doi.org/10.1093/bjps/axy039.

Frey, D., \& Šešelja, D. (2018b). What is the epistemic function of highly idealized agent-based models of scientific inquiry? Philosophy of the Social Sciences. https://doi.org/10.1177/0048393118767085.

Gilbert, N. (1997). A simulation of the structure of academic science. Sociological Research Online, 2(2), $1-15$.

Goldman, A. I., \& Shaked, M. (1991). An economic model of scientific activity and truth acquisition. Philosophical Studies, 63(1), 31-55.

Grim, P. (2009). Threshold phenomena in epistemic networks. In AAAI fall symposium: Complex adaptive systems and the threshold effect (pp. 53-60).

Grim, P., Singer, D. J., Fisher, S., Bramson, A., Berger, W. J., Reade, C., et al. (2013). Scientific networks on data landscapes: Question difficulty, epistemic success, and convergence. Episteme, 10(04), 441-464.

Harnagel, A. (2018). A mid-level approach to modeling scientific communities. Studies in History and Philosophy of Science. https://doi.org/10.1016/j.shpsa.2018.12.010.

Heesen, R. (2018a). When journal editors play favorites. Philosophical Studies, 175(4), 831-858. https ://doi.org/10.1007/s11098-017-0895-4.

Heesen, R. (2018b). Why the reward structure of science makes reproducibility problems inevitable. The Journal of Philosophy, 115(12), 661-674.

Hegselmann, R., \& Krause, U. (2002). Opinion dynamics and bounded confidence: Models, analysis, and simulation. Journal of Artificial Societies and Social Simulation, 5(3). http://jasss.soc.surre y.ac.uk/5/3/2.html. 
Hindriks, F. (2008). False models as explanatory engines. Philosophy of the Social Sciences, 38(3), 334-360.

Holman, B., \& Bruner, J. (2015). The problem of intransigently biased agents. Philosophy of Science, 82(5), 956-968.

Kitcher, P. (1990). The division of cognitive labour. The Journal of Philosophy, 87(1), 5-22.

Kitcher, P. (1993). The advancement of science: Science without legend, objectivity without illusions. Oxford: Oxford University Press.

Mäki, U. (2005). Economic epistemology: Hopes and horrors. Episteme, 1(03), 211-222.

Martini, C., \& Pinto, M. F. (2016). Modeling the social organization of science. European Journal for Philosophy of Science, 7, 1-18.

Modgil, S., \& Prakken, H. (2014). The ASPIC+ framework for structured argumentation: A tutorial. Argument and Computation, 5(1), 31-62.

Mohseni, A., O'Connor, C., \& Rubin, H. (2019). On the emergence of minority disadvantage: Testing the cultural red king hypothesis. Synthese. https://doi.org/10.1007/s11229-019-02424-1.

Muldoon, R. (2013). Diversity and the division of cognitive labor. Philosophy Compass, 8(2), 117-125.

Muldoon, R., \& Weisberg, M. (2011). Robustness and idealization in models of cognitive labor. Synthese, 183(2), 161-174.

Nickles, T. (2017). Historicist theories of scientific rationality. In E. N. Zalta (Ed.), The Stanford encyclopedia of philosophy. Stanford: Metaphysics Research Lab, Stanford University.

O'Connor, C., \& Weatherall, J. O. (2018). Scientific polarization. European Journal for Philosophy of Science, 8(3), 855-875.

O’Sullivan, D., Evans, T., Manson, S., Metcalf, S., Ligmann-Zielinska, A., \& Bone, C. (2016). Strategic directions for agent-based modeling: Avoiding the yaawn syndrome. Journal of Land Use Science, 11(2), 177-187.

Payette, N. (2012). Agent-based models of science. In A. Scharnhorst, K. Bórner, \& P. van den Besselaar (Eds.), Models of science dynamics, understanding complex systems (pp. 127-157). Berlin: Springer.

Perović, S., \& Sikimić, V. (2019). How theories of induction can streamline measurements of scientific performance. Journal for General Philosophy of Science. https://doi.org/10.1007/s10838-019-09468-4.

Pöyhönen, S. (2017). Value of cognitive diversity in science. Synthese, 194(11), 4519-4540.

Romero, F. (2016). Can the behavioral sciences self-correct? A social epistemic study. Studies in History and Philosophy of Science Part A, 60, 55-69. https://doi.org/10.1016/j.shpsa.2016.10.002.

Rosenstock, S., O'Connor, C., \& Bruner, J. (2017). In epistemic networks, is less really more? Philosophy of Science, 84(2), 234-252.

Santana, C. (2019). Let's not agree to disagree: The role of strategic disagreement in science. Synthese. https ://doi.org/10.1007/s11229-019-02202-z.

Šešelja, D. (2019). Some lessons from simulations of scientific disagreements. Synthese. https://doi. org/10.1007/s11229-019-02182-0.

Šešelja, D., \& Straßer, C. (2013). Abstract argumentation and explanation applied to scientific debates. Synthese, 190, 2195-2217.

Strevens, M. (2003). The role of the priority rule in science. The Journal of philosophy, 100(2), 55-79.

Thicke, M. (2019). Evaluating formal models of science. Journal for General Philosophy of Science. https:// doi.org/10.1007/s10838-018-9440-1.

Thoma, J. (2015). The epistemic division of labor revisited. Philosophy of Science, 82(3), 454-472.

van Lee, H. S., \& Smets, S. (2019). The logic of observation and belief revision in scientific communities. Journal for General Philosophy of Science. https://doi.org/10.1007/s10838-018-9436-x.

Weatherall, J. O., O'Connor, C., \& Bruner, J. (2018). How to beat science and influence people: Policy makers and propaganda in epistemic networks. The British Journal for the Philosophy of Science. https:// doi.org/10.1093/bjps/axy062.

Weisberg, M., \& Muldoon, R. (2009). Epistemic landscapes and the division of cognitive labor. Philosophy of Science, 76(2), 225-252.

Zamora Bonilla, J. P. (2002). Scientific inference and the pursuit of fame: A contractarian approach. Philosophy of Science, 69(2), 300-323.

Zollman, K. J. S. (2007). The communication structure of epistemic communities. Philosophy of Science, 74(5), 574-587.

Zollman, K. J. S. (2010). The epistemic benefit of transient diversity. Erkenntnis, 72(1), 17-35.

Publisher's Note Springer Nature remains neutral with regard to jurisdictional claims in published maps and institutional affiliations. 